\title{
Lipid Profile in Hypothyroid Patients: A Cross Sectional Study
}

\author{
Khan $\mathrm{MAH}^{1}$, Majumder $\mathrm{I}^{2}$, Hoque $\mathrm{MM}^{3}$, Fariduddin $\mathrm{M}^{4}$, Mollah $\mathrm{FH}^{5}$, Arslan $\mathrm{MI}^{6}$
}

\begin{abstract}
Abstact
Hypothyroidism is an important metabolic disorder and is associated with many biochemical abnormalities. Many studies were done regarding the biochemical status of hypothyroid patients including lipid profile. But controversies still prevail. So, a cross sectional study was done in our population to evaluate lipid profile status of hypothyroid patients compared to age and sex matched healthy euthyroid persons. In our study mean serum total cholesterol, LDL cholesterol and triacylglycerol levels in cases and controls were $241.56 \pm 60.05$ vs $146.94 \pm 23.21$ $\mathrm{mg} / \mathrm{dL}, 151.96 \pm 59.60 \mathrm{vs} 71.43 \pm 26.83 \mathrm{mg} / \mathrm{dL}$ and $212 \pm$ 100.73 vs $98.87 \pm 39.69 \mathrm{mg} / \mathrm{dL}$ respectively with $p$ values $<0.001$ whereas HDL cholesterol was found significantly decreased in cases compared to controls $(49.59 \pm 11.69 \mathrm{vs}$ $55.89 \pm 11.70 \mathrm{mg} / \mathrm{dL}$ with $p$ value $<0.05)$. Results of our study suggest that dyslipidemias are associated with hypothyroidism. Therefore, patients presenting with dyslipidemia are recommended for investigation to explore hypothyroidism
\end{abstract}

Key words: Hypothyroidism, total cholesterol, triglycerides, LDL cholesterol, HDL cholesterol

\section{Introduction}

Hypothyroidism is a clinical syndrome resulting from a deficiency of thyroid hormones, which in turn results in a generalized slowing down of metabolic processes ${ }^{1}$. It is a common metabolic disorder in general population ${ }^{2}$. The thyroid dysfunction increases with age, especially in women ${ }^{3}$.

Hypothyroidism is associated with many biochemical abnormalities. Levels of total cholesterol and low density lipoprotein cholesterol tend to increase as thyroid function

1. Corresponding Author:

Md. Aminul Haque Khan MCPS, FCGP, FCPS, MD

Professor, Department of Biochemistry

Enam Medical College, Savar, Dhaka

E-mail: aminhkhan@yahoo.com

2. Ishaque Majumder

Assistant Professor, Department of Medicine

Sir Salimullah Medical College, Dhaka

3. Md. Mozammel Hoque

Professor, Department of Biochemistry

Bangabandhu Sheikh Mujib Medical University, Dhaka

4. Md. Fariduddin

Professor, Endocrinology \& Metabolism, Department of Medicine

Bangabandhu Sheikh Mujib Medical University, Dhaka

5. Forhadul Hoque Mollah

Associate Professor, Department of Biochemistry

Bangabandhu Sheikh Mujib Medical University, Dhaka

6. M Iqbal Arslan

Professor, Department of Biochemistry

Bangabandhu Sheikh Mujib Medical University, Dhaka declines ${ }^{2}$. Thus hypothyroidism constitutes a significant cause of secondary dyslipidemia ${ }^{4}$. In hypothyroid patients, despite the reduced activity of HMG CoA reductase, there is often an increase in the serum total cholesterol concentration, mainly due to raised levels of serum LDL cholesterol and intermediate density lipoprotein (IDL) cholesterol $^{5}$. Decreased thyroid secretion greatly increases the plasma concentration of cholesterol because of decreased rate of cholesterol secretion in the bile and consequent diminished loss in the feces due to decreased number of low density lipoprotein receptors on liver cells $s^{6}$. Decreased activity of LDL receptors resulting in decreased receptor-mediated catabolism of LDL and IDL is the main cause of the hypercholesterolemia observed in hypothyroidism? ${ }^{7}$.

Serum concentration of high density lipoprotein cholesterol was reported to be higher among newly diagnosed hypothyroid patients with the value more than $40 \mathrm{mg} / \mathrm{dL}$ in subclinical or clinical hypothyroidism whereas serum concentrations of HDL cholesterol were significantly lower among euthyroid and previously reported hypothyroid cases who were on thyroid replacement therapy ${ }^{8}$. Hypothyroid patients usually exhibit elevated levels of high density lipoprotein cholesterol (HDL-C) mainly due to increased concentration of $\mathrm{HDL}_{2}$ particles 9 . In some studies we find confronting results regarding high density lipoprotein cholesterol levels in hypothyroidism. In thyroidectomized rats there was $25.9 \%$ decrease in HDL-C level, suggesting a defect in HDL metabolism ${ }^{10}$. HDL cholesterol level was found reduced in some other studies on hypothyroid patients?.

Decreased thyroid secretion greatly increases the plasma concentration of triglycerides ${ }^{6}$. Nikkilia \& $\mathrm{Kekki}^{11}$ have stated that hypertriglyceridemia in hypothyroidism is due to decreased activity of lipoprotein lipase (LPL), which results in decreased clearance of triglyceride-rich lipoproteins.

Dyslipidemia is a well-known risk factor for cardiovascular diseases. The risk of coronary heart disease and other forms of atherosclerotic vascular disease rises with rising plasma cholesterol concentration and in particular with rising ratio of total cholesterol to high density lipoprotein (HDL) cholesterol. A weak positive correlation of coronary heart disease also exists with plasma triglyceride concentration ${ }^{12}$. Early diagnosis and proper management can significantly reduce the mortality and morbidity of dyslipidemic cardiovascular diseases. Extensive large-scale randomized trials have shown that lowering total cholesterol and LDL cholesterol reduces the risk of cardiovascular events like angina, myocardial infarction and stroke, and also reduces the need for revascularization ${ }^{12}$. 
Many studies were done to assess the lipid profile status of hypothyroid patients. But controversies still prevail and that needs to attain consensus. So, we have designed this study in our population for evaluation of lipid profile in hypothyroid patients that might be helpful for clinical management of hypothyroid patients with dyslipidemia.

\section{Materials and Methods}

This cross sectional study was conducted in the department of Biochemistry of Bangabandhu Sheikh Mujib Medical University, Dhaka to evaluate the lipid profile of hypothyroid patients and to find out relationship of dyslipidemia with severity of hypothyroidism. Clinically and biochemically newly diagnosed hypothyroid patients of both sexes, age 20 to 60 years, with no history of thyroxine and hypolipidemic drugs in the last 3 (three) months were included in the study. Patients with chronic renal failure, diabetes mellitus, liver diseases, chronic diseases, pregnancy and age less than 20 and more than 60 years were excluded. Hypothyroidism was diagnosed by clinical history, physical examinations and relevant laboratory investigations. Total 111 subjects were included in the study and out of them 80 overt hypothyroid patients were grouped as cases (Group I) and 31 euthyroid subjects were grouped as normal controls (Group II). Cases were further grouped on the basis of their serum TSH concentration into Group A (TSH level 5.01-50.00 mIU/L), Group B (TSH 50.00$100.00 \mathrm{mIU} / \mathrm{L})$ and Group C (TSH level>100.00 mIU/L). Specimen was collected in fasting condition, allowed to clot; serum was separated and analyzed for serum total cholesterol, triacylglycerol and HDL cholesterol levels. LDL cholesterol level was calculated by Friedewald's equation.

\section{Statistical analysis}

Statistical analyses were performed by using SPSS for Windows version 12.0. Mean values of the findings were compared among and between groups. Analysis of variance (ANOVA) test and Unpaired ' $t$ ' test were done to assess the significance among the groups and between groups respectively. Pearson correlation coefficient test was done to evaluate the correlation of biochemical parameters with the severity of hypothyroidism. 'p' values $<0.05$ were considered significant.

\section{Results}

Table I shows the comparison of the lipid profile parameters between the cases and the controls. Mean total cholesterol, HDL cholesterol, LDL cholesterol and triglycerides level in cases were higher than controls. HDL cholesterol was found significantly decreased in cases compared to controls.

Table II shows lipid profile parameters in different groups of cases. There was no significant difference among the groups for serum total cholesterol, but a rising trend was found from Group A to Group C. For HDL cholesterol levels, significant differences were observed among the groups with maximum in Group B and minimum in Group C. Mean LDL cholesterol levels showed significant difference among the groups with maximum in Group $\mathrm{C}$ and minimum in Group A. Mean serum triglyceride levels showed no significant difference among groups.

Table I: Lipid profile of study subjects

\begin{tabular}{lllc}
\hline \multicolumn{1}{c}{ Parameters } & Cases $(\mathbf{n = ~ 8 0})$ & Controls $(\mathbf{n}=31)$ & 'p' values \\
\hline Total cholesterol $(\mathrm{mg} / \mathrm{dL})$ & $241.56 \pm 60.05$ & $146.94 \pm 23.21$ & $<0.001$ \\
HDL cholesterol $(\mathrm{mg} / \mathrm{dL})$ & $49.59 \pm 11.69$ & $55.89 \pm 11.70$ & $<0.05$ \\
LDL cholesterol $(\mathrm{mg} / \mathrm{dL})$ & $151.96 \pm 59.60$ & $71.43 \pm 26.83$ & $<0.001$ \\
Triglycerides $(\mathrm{mg} / \mathrm{dL})$ & $212.28 \pm 100.73$ & $98.87 \pm 39.69$ & $<0.001$ \\
\hline
\end{tabular}

Table II: Lipid profile in different groups of cases

\begin{tabular}{lllll}
\hline Parameters & $\begin{array}{l}\text { Group A } \\
(\mathbf{n = 1 4})\end{array}$ & $\begin{array}{l}\text { Group B } \\
(\mathbf{n = 2 9})\end{array}$ & $\begin{array}{l}\text { Group C } \\
(\mathbf{n}=37)\end{array}$ & $\begin{array}{c}\text { 'p' } \\
\text { values }\end{array}$ \\
\hline $\begin{array}{l}\text { Total cholesterol } \\
(\mathrm{mg} / \mathrm{dL})\end{array}$ & $215.93 \pm 43.25$ & $237.10 \pm 64.49$ & $254.76 \pm 59.61>0.05$ \\
$\begin{array}{l}\text { HDL cholesterol } \\
(\mathrm{mg} / \mathrm{dL})\end{array}$ & $51.36 \pm 9.84$ & $53.34 \pm 13.01$ & $45.97 \pm 10.35$ & $<0.05$ \\
$\begin{array}{l}\text { LDL cholesterol } \\
(\mathrm{mg} / \mathrm{dL})\end{array}$ & $119.64 \pm 45.00$ & $150.41 \pm 61.28$ & $165.41 \pm 59.57<0.05$ \\
$\begin{array}{l}\text { Triglycerides } \\
(\mathrm{mg} / \mathrm{dL})\end{array}$ & $224.36 \pm 88.83$ & $221.16 \pm 112.39$ & $221.16 \pm 112.39>0.05$ \\
\hline
\end{tabular}

Table III shows correlation between serum free thyroxine level and lipid profile parameters of cases. FT4 has shown significant negative correlation with serum total cholesterol, LDL cholesterol and triglyceride levels. No correlation was found between serum FT4 level and serum HDL cholesterol level.

Table IV shows correlation between serum TSH level and lipid profile parameters of cases. Total cholesterol and LDL cholesterol were found to maintain significant positive correlation with serum TSH. But TSH was found to show no correlation with serum HDL cholesterol and serum triglycerides level.

Table III: Correlation between free thyroxine level and lipid profile of cases

\begin{tabular}{|l|lll|}
\hline \multirow{3}{*}{ FT4 } & Lipid profile in $\mathrm{mg} / \mathrm{dL}$ & $\mathrm{r}$ values & 'p' values \\
\cline { 2 - 4 } (in $\mathrm{pmol} / \mathrm{L})$ & Total cholesterol & -.278 & $<0.05$ \\
& HDL cholesterol & .020 & $>0.05$ \\
& LDL cholesterol & -.238 & $<0.05$ \\
& Triglycerides & -.278 & $<0.05$ \\
\hline
\end{tabular}

Table IV: Correlation between TSH level and lipid profile of cases

\begin{tabular}{|c|c|c|c|}
\hline \multirow{5}{*}{$\begin{array}{l}\text { TSH } \\
\text { (in mIU/L) }\end{array}$} & Lipid profile in $\mathrm{mg} / \mathrm{dL}$ & r values & 'p' values \\
\hline & Total cholesterol & .221 & $<0.05$ \\
\hline & HDL cholesterol & -.026 & $>0.05$ \\
\hline & LDL cholesterol & .261 & $<0.05$ \\
\hline & Triglycerides & -.138 & $>0.05$ \\
\hline
\end{tabular}

\section{Discussion}

Hypothyroidism is a common metabolic disorder. The prevalence of primary hypothyroidism is $1: 100$, but it may 
be 5:100 if patients with subclinical hypothyroidism (normal $\mathrm{T} 4$, raised TSH) are included ${ }^{13}$. According to a study done by Sawin ${ }^{14}$, hypothyroidism is a common disorder with a prevalence rate up to $20 \%$. In another cross-sectional study on twelve hundred and twelve subjects of both sexes and age 20-60 years, the incidence of subclinical hypothyroidism was $19.7 \%$.

In our study, mean total cholesterol, LDL cholesterol and triglycerides were found significantly increased whereas HDL cholesterol was found significantly decreased in cases compared to controls. Jung ${ }^{16}$ found mean plasma total cholesterol and LDL cholesterol levels elevated in hypothyroid cases than in normal controls. In another study, average serum total cholesterol level was found elevated in primary and secondary hypothyroidism ${ }^{17}$. Keyes \& Heimberg ${ }^{18}$, Laker \& Mayes ${ }^{19}$ found triglyceride level elevated in hypothyroid patients. So, our study findings were consistent with the previous studies done by other investigators.

Thompson ${ }^{7}$ and Abrams \& Grundy ${ }^{20}$ have stated decreased activity of LDL receptors as the main cause of hypercholesterolemia in hypothyroidism.

Serum concentrations of high density lipoprotein cholesterol was reported to be higher among newly diagnosed hypothyroid patients (subclinical or clinical) whereas serum concentrations of HDL cholesterol were significantly lower among euthyroid and previously reported hypothyroid cases who were on thyroxine replacement therapy ${ }^{8}$. Studies done by Michalopoulou ${ }^{21}$, Diekman ${ }^{22}$, Tsmihodimos ${ }^{23}$ and Olukoga ${ }^{24}$ showed average serum concentration of HDL higher in subclinical or clinical hypothyroidism. But, on the other hand, in a study on thyroidectomized rats, HDL-C showed a $25.9 \%$ decrease compared to controls ${ }^{10}$. In another study on thyroidectomized rats, there was $25 \%$ decrease in HDL cholesterol level compared to control rats ${ }^{25}$. Abrams \& Grundy 20 have shown in their studies reduction of HDL cholesterol in hypothyroidism. So, our study is consistent with some of the studies and inconsistent with the others. A large scale study on overt hypothyroid patients is recommended to come to a final conclusion.

Increase in HDL cholesterol concentration is mainly due to increased concentration of $\mathrm{HDL}_{2}$ particles ${ }^{9}$. Dullaart ${ }^{26}$ have stated that decreased activity of CETP (cholesteryl ester transport protein) results in reduced transfer of cholesteryl esters from HDL to VLDL, thus increasing HDL cholesterol levels. Lam $^{27}$ have stated that in hypothyroid patients decreased activity of hepatic lipase leads to the decreased catabolism of $\mathrm{HDL}_{2}$ particles leading to increased HDL. So, decrease in HDL cholesterol level in our study might be due to increased activity of CETP and lipoprotein lipase in hypothyroid patients.

There was no significant difference in serum total cholesterol concentrations among the groups, but a rising trend was found from Group A to Group C ( $p=0.0395)$, making our results apparently consistent with the severity of hypothyroidism. This theme seems to be further consolidated by increasing LDL concentrations in line with the increasing severity of hypothyroidism from Group A to Group $\mathrm{C}$ as revealed in our study. This is further strengthened by our findings of negative correlation of FT4 and positive correlation of TSH with total cholesterol and LDL cholesterol levels.

Significant difference in serum HDL cholesterol levels was observed among the groups with maximum in Group B and minimum in Group C. This finding partially indicates the lowest HDL with maximum degree of hypothyroidism. But the characteristic pattern of decreasing HDL with increasing severity of hypothyroidism could not be revealed in this study. This is further supported by our finding of no correlation of HDL with FT4 or TSH. This might be due to our small sample size.

Regarding triglycerides levels, no significant difference was found among the groups, indicating no changing impact on triglycerides metabolism with severity of hypothyroidism. It is claimed that thyroid hormones facilitate the LPL activity $^{11}$, but deficiency of thyroid hormones to inhibit LPL probably follows a ceiling point beyond which further reduction of thyroid hormones does not cause further inhibition of LPL.

In our study FT4 has shown significant negative correlation with serum total cholesterol, LDL cholesterol and triglycerides level. No correlation was found between serum FT4 level and serum HDL cholesterol level. Total cholesterol and LDL cholesterol were found to maintain significant positive correlation with serum TSH. But TSH was found to show no correlation with serum HDL cholesterol and serum triglycerides level. Significant negative correlation of FT4 with triglycerides level and no correlation of TSH with triglycerides appear to make a sense of functional disharmony between FT4 and TSH and, therefore, a large scale study is recommended to make it clear.

Results of our study suggest the findings of dyslipidemia in hypothyroid patients. Therefore, patients presenting with dyslipidemia are recommended to be investigated for hypothyroidism. As our sample size was small and duration of study was limited, another study with large sample size and longer duration is also recommended.

\section{References}

1. Greenspan FS. The thyroid gland. In: Greenspan FS \& Gardner DG (eds). Basic \& Clinical Endocrinology. 7th edn. New York: The McGraw-Hill Companies, 2004:215-294.

2. Liberopoulos EN, Elisaf MS. Dyslipidemia in patients with thyroid disorders. Available at: http://www.endocrine-society.gr/hormones/pdf/4 2002/05 liberopoulos.pdf, Greece: Moses S Elisaf, 2002. 
3. Duntas LH. Thyroid disease and lipids. Thyroid 2002;12:287-293.

4. Tsimihodimos V, Bairaktari E, Tzallas C, Miltiadus G, Liberopoulos E, Elisuf M. The incidence of thyroid function abnormalities in patients attending an outpatient lipid clinic. Thyroid 1999;9:365-368.

5. Stone NJ. Secondary causes of hyperlipidemia. Med Clin North Am 1994;78:117-141.

6. Guyton AC, Hall JE. The thyroid metabolic hormones. In: Textbook of medical physiology. 10th edn. New York: W B Saunders Company, 2000:858-868.

7. Thompson GR, Soutar AK, Spengel F A, Jadhav A, Gavigan S, Myant NB. Defects of the receptormediated low density lipoprotein metabolism in homozygous familiar hypecholesterolemia and hypothyroidism in vivo. Proct Natl Acad Sci USA 1981;78:2591-2595.

8. de Castro AV, Bononi AP, Aragon F, Padovani CR, Nogueira CR, Mazeto GM, Pimenta. Clinical and laboratory evaluation of hyperlipemia and hypothyroid patients. Arq Bras Cardiol 2001;76:119-126.

9. Heimberg M, Olubadewo JO, Wilcox HG. Plasma lipoproteins and regulation of hepatic metabolism of fatty acids in altered thyroid states. Endocrine Rev 1985;6:590-607.

10. Huesca-Gomez C, Franco M, Luc G, Montano LF, Masso F, Posadas-Romero C, Perez-Mendez O. Chronic hypothyroidism induces abnormal structures of high-density lipoproteins and impaired kinetics of apolipoprotein A-I in the rat. Metabolism 2002;51:443450.

11. Nikkilia EA, Kekki M. Plasma triglyceride metabolism in thyroid disease. J Clin Invest 1972;51:2103-2114.

12. Boon NA, Fox KAA, Bloomfield P, Bradbury A. Cardiovascular disease. In: Haslett C, Chilvers ER, Boon NA, Colledge NR (eds). Davidson's principles and practice of medicine. 19th edn. London: Churchill Livingstone, 2002:357-481.

13. Walker BR, Toft AD. Endocrine disease. In: Haslett C, Chilvers ER, Boon NA, Colledge NR (eds). Davidson's principles and practice of medicine. 19th edn. London: Churchill Livingstone, 2002:683-746.

14. Sawin CT, Castelli WP, Hershman JM, McNamara P, Bacharach P. The aging thyroid: thyroid deficiency in the Framingham study. Arch Intern Med 1985; $145: 1386-1388$.

15. Kventy J, Heldgaard PE, Bladbjerg EM, Gram J. Subclinical hypothyroidism is associated with a low grade inflammation, increased triglyceride levels and predicts vascular disease in males below 50 years. Clin Endocrinol 2004;61:232-238.

16. Jung CH, Sung KC, Shin HS, Rhee EJ, Lee WY, Kim BS, Kang JH, Kim H, Kim SW, Lee MH, Park JR, Kim SW. Thyroid dysfunction and their relation to cardiovascular risk factors such as lipid profile, hsCRP and waist hip ratio in Korea. Korean J Intern Med 2003;18:146-153.

17. Skanse B. On the difference in serum cholesterol between hypothyroidism of pituitary and of thyroid origin. In: Pitt-Rivers R, Green R, Tata JR, McCartney W, Taylor S, Pochin EE, Trotter WR (eds). The fourth international goitre conference. London: Pergaman Press, 1961:108-118.

18. Keyes WG, Heimberg M. Influence of thyroid status on lipid metabolism in the perfused rat liver. J Clin Invest 1979;64:182-190.

19. Laker ME, Mayes PA. Effect of hyperthyroidism and hypothyroidism and carbohydrate metabolism of the perfused rat. Biochem J 1981;96:247-255.

20. Abrams JJ, Grundy SM. Cholesterol metabolism in hypothyroidsm and hyperthyroidism in man. J Lipid Res 1981;82:323-338.

21. Michalopoulou G, Alevizaki M, Piperingos G, Mitsibounas D, Mantzos E, Adampoulos P et al. High serum cholesterol levels in persons with 'high normal' TSH levels: should one extend the definition of subclinical hypothyroidism? Eur J Endocrinol 1998;138:141-145.

22. Diekman T, Lansberg PJ, Kastelein JJP, Wiersinga WM. Prevalence and correction of hypothyroidism in a large cohort of patients referred for dyslipidemia. Arch Intern Med 1995;155:1490-1495.

23. Tsimihodimos V, Bairaktari E, Tzallas C, Miltiadus G, Liberopoulos E, Elisaf M. The incidence of thyroid function abnormalities in patients attending an outpatient lipid clinic. Thyroid 1999;9:365-368.

24. Olukago AO, Crowly VEF, Lawal A, Kleinkov C. Hyperlipidemia and hypothyroidism: screening patients for hypothyroidism before treatment. $\mathrm{Br}$ Med J 1994;308:918.

25. Franco M, Castro G, Romero L, Regalado JC, Medina A, Huesca-Gomez C, Ramirez S, Montano LF, Posadas-Romero C, Perez-Mendez O. Decreased activity of lecithin: cholesterol acyltransferase and hepatic lipase in chronic hypothyroid rats: implications of reverse cholesterol transport. Mol Cell Biochem 2003;246:51-56

26. Dullaart RP, Hoogenberg K, Groener JE, Dikkeschei LD, Erkelens DW, Doorenbos H. The activity of cholesteryl ester transfer protein is decreased in hypothyroidism: a possible contribution to alterations in high-density lipoproteins. Eur $\mathrm{J}$ Clin Invest 1990;20:581-587.

27. Lam KS, Chan MK, Yeung RT. High-density lipoprotein cholesterol, hepatic lipase and lipoprotein lipase activities in thyroid dysfunction - effect of treatment. Q J Med 1986; 59: 513-521. 